\title{
Taboos in China: To Be or Not to Be
}

\author{
Fuyu Chen ${ }^{1}$ \\ ${ }^{1}$ College of Foreign Languages, Chongqing Jiaotong University, China \\ Correspondence: Fuyu Chen, College of Foreign Languages, Chongqing Jiaotong University, 66 Xuefu Avenue, \\ Nan'an, Chongqing 400074, China. Tel: 86-23-6277-8043. E-mail: eric97073@yahoo.com.cn
}

Received: February 24, 2012 Accepted: March 7, 2012 Online Published: July 1, 2012

doi:10.5539/elt.v5n7p123 URL: http://dx.doi.org/10.5539/elt.v5n7p123

\begin{abstract}
With powerful influence on the people, taboos should be noticed with keen awareness and handled with cautious respect for international visitors in China, a traditional country in its process of modernization, if successful cross-cultural communication is to be achieved. In the ever changing and integrating world, Chinese taboos are never free from differentiation: some are permant; some are newly shaped; some are weakening; and some have even totally disappeared. The introduction of Chinese taboos in different aspects of life and their tendency of development should hopefully provide help for those from the rest of the world to overcome cultural barriers in relation with the Chinese people.
\end{abstract}

Keywords: Chinese taboos, cross-cultural communication, speaking rules, changes

\section{Introduction}

Globalization has changed China drastically, while in turn, based on its huge population and increasing economic share in the world market, China has an increasingly greater influence on the rest of the world. Through sino-foreign communications, on the one hand, the Chinese people have taken in many foreign elements in every aspect of life; on the other hand, foreigners living in China or intending to visit this country have already begun or are beginning to learn about the Chinese culture: the likes and dislikes of the people, the ways to relate to the citizens, the etiquettes appropriate for a variety of social occasions, etc.

This paper focuses on the taboos in the Chinese society, a basic yet significant part for cross-cultural communication, the knowledge and respect of which is generally considered as a speaking rule and a cooperative principle. As China has unergone over the years and is presently undergoing unprecedented social changes like the other parts of the world, taboos therein are also under the influence of globalization. Some of Chinese taboos are permanent; some have changed considerably; some have even totally disappeared. Taboos in China, similar to those in other countries, involves numbers, money, colors, religion, marriage, death and disease, physical and psychological conditions, etc. Some of such taboos are to be found nationwide, while the rest may be only exercised regionally, or even by a very small group of people. Through the analysis of the existing, changing and to-be taboos in China, it is hoped that this paper would somehow serve as a communication guidance for international visitors to China and help them overcome the cultural difficulty in relation with the Chinese people.

\section{Numbers as Taboos}

There are some numbers in Chinese culture which are of significant meanings. One typical example is " 8 " (ba), whose pronunciation happens to resemble "fa" (to become rich /to make money). Therefore, " 8 " is always preferred by most people in China. However, some numbers are never liked in China, for instance the number "4" (Gao, 2010).

\subsection{4 and 4-Related Numbers}

\subsubsection{General and Traditional Taboo}

The very reason that " 4 " is generally ragarded as a strict traditional taboo in China is phonetical. In mandarin Chinese and most dialects, "4" is pronounced as "si" (fourth tone), very much close to the other "si" (third tone) which means death/to die. Numbers with "4" are generally considered unfavorable, the worst of which is " 14 ". In Chinese "14" is usually pronounced as "yaosi", euphony of "dying/to die".

This affects many things in Chinese life. For example, when people are to deliver "red-pack money" to newly weds, they are not expected to give $¥ 400$, for it is inauspicious. 
Similarly, when people are to purchase a real estate, it is not uncommon that they would avoid choosing apartments on the $4^{\text {th }}$ floor. If so unfortunately they have to buy a 4-floor real estate, they would try best to keep away from "4" in the room number. Therefore, it can be noted that properties on the $3^{\text {rd }}$ and $5^{\text {th }}$ floors are always better sold than those on the $4^{\text {th }}$ floor. While estates numbered " 404 " or " 444 ", if any, would remain empty for a long long time.

In hotels and hospitals, rooms numbered with "4" or " 14 " are seldom to be found. Many of such buildings have excluded such numbers for rooms. The following example is a proof.

One professor went to meet the department director in the office. Guided by the building directory, he looked for Room 514 but failed. He was finally welcomed by the director in Room 516 and was told there was no Room 514, simlpy because " 514 " sounded the same as "I am dying".

\subsubsection{Recent Changes}

In cross-cultural communication, people in China have gradually come to know that "4" is not a taboo in western cultures: Thanksgiving on the $4^{\text {th }}$ Thursday in November, U.S. Independence on July $4^{\text {th }}$, etc. This understanding has given rise to some changes in the situation, best noticed in trades and commerce.

On the one hand, based on their reputation, product quality and sales promotion strategy, many international manufacturers have enjoyed great success in China. Motor manufacturer Audi, with its 4-circle logo, finds its cars among the most popular in China. French producer Citroen sells well its cars branded Ce Quartre (literally "4"). Apple's Iphone 4 is welcomed as much as its predecessors.

On the other hand, domestic market operators of digital service are beginning to bring the 4-related and long-wasted resources into use. Targetting at people of lower income, they provided considerable discount for buyers of cellphone cards and fixed telephones numbered with "4". Similar is the case of car numbers with "4". Out of necessity and their ecnomic conditions, such people, primarily students and migrant workers, have deemed the deal acceptable.

An important and popular interpretation of " 4 " in recent years is a musical approach. The resaon is that in Chinese music tones, "4" sounds exactly "fa" (to become rich /to make money). Hence when someone gets a " 4 ", he would comfort himself in that way.

\subsection{3}

The number "13" as a taboo is an introduced and new concept in China, where the major beliefs are Buddism and Taoism. With more and more international visitors going to China, for tour or on business, and some of them are even naturalized as Chinese citizens, an increasing number of Chinese have come to realized western taboos and tended to be cautious in relation with foreigners.

Thus when they are to book hotel rooms for guests from abroad, they would definitely avoid the number "13", and they would not arrange meetings in rooms numbered with " 13 ".

It is interesting enough to notice that the maximum number of participants in dinners with foreigners is 12 , because both "13" and "14" are taboos on such occasion.

The taboo of " 13 " is nowadays observed by an increasingly large portion of Chinese, particlularly in higher education organizations where there are more and more international teachers and students, in governmental offices and tourism agencies where it is an important part of the work to receive foreign visitors, and in companies which are engaged in international cooperations.

\subsection{3 and 84}

To most advanced Chinese people, " 73 " and " 84 " are taboos, which is well reflected in the saying "At the age of 73 or 84, even if the King of Hell does not summon, one would go there on his own initiative." This jokingly sentence implies the fear of death among the aged population. The origin of "73 and 84 " taboo can be dated back to the Spring and Autumn Period about 3,000 years ago. Records show the two sages Confucius and Mencius passed away at the ages of 73 and 84 respectively. Even the saints could not escape the Law of Nature. Therefore many people believe 73 and 84 are the destined years for them to leave this world, which has become a heavy psychological burden.

As a result, foreigners communicating with the elderly in China should be keenly aware of the age taboo. Although most of the time, age represents experience and respect, it could also be something very sensitive (Lin, 1996:121).

\section{Money-Related Taboos}

Like in other countries, money has become a sensitive topic in personal communication in China. Over the past decades, taboo subjects related to money have undergone great changes. 


\subsection{Income}

Income was not a taboo subject in China until the end of the $20^{\text {th }}$ century. Before then, the income of a great majority of people was transparent when levels of wages were open to the pulic and very close between different fields and different positions. Farmers, workers, teachers, officials, people loved talking about how much they had earned and it was a habit to inquire the income of their friends and relatives. And the inquired were willing to answer. In nearly half a century and from cities to villages, such kind of inquiry and comparison had been of great fun and served as a drive force in people's life.

However, with the implementation of the opening-up policy and the progress of marketing economy, employment in different fields are paid differently; even in the same field, there could be a variety of wage levels: the highest could double or even triple the lowest. Especially as new years come, when the employees receive the yearly bonus by the boss as a tradition, they would discover the difference in the amount of money sealed in each envelope. Thus, conversations on income become less and less since 1990s.

The very silence over income is due to two factors. On the one hand, some employees with a humble income are unwilling to talk over it, because they deem it a disgrace but a matter of dignity. On the other hand, emploees with a higher income are aslo unwilling to talk about it, because they do not want to arouse envy or sense of unfairness among the colleagues. Besdies, talking about the income is regarded as an indirect comment on the boss, which both parts of employees would avoid.

It is now generally accepted that income is a strict taboo in China. It is very impolite to inquire about the income of the other during a talk, unless you are either a family member or a very close friend of that person.

\subsection{Prices of Bought Commodities}

Similar to the case of income, public attitudes towards prices have also gone through dramatic changes. In the second half of the $20^{\text {th }}$ century when the majority of Chinese population were endeavoring to make a living, it was generally considered an honor to save money. One of the most popular topics between people, particularly between women, was a comparison of the prices of what they had bought, including clothes, bicycles, watches, casette players, etc. And the one with the lowest price would definitely take pride in it, as if s/he were the winner of a battle.

But the situation seemed to have reversed since the turn of century. With the growth of income as the national economy continues rapidly developing and globalization accelerates sweeping through China, more and more people nowadays tend to purchase quality but expensive commodities, either tradtional or fashionable, from garments to ornaments, from cellphones to automobiles. What was once something to be proud of is replaced by products of a better quality and a higher price. Hence prices have become a matter of not only money but, more importantly, a matter of dignity. To quite many people, it has become a shame to be not able to afford expensive and good (?) things, for in their eyes, a lower price may indicate a lower income and a lower social status.

Consequently, in social conversations, prices are no longer an appropriate topic in China and foreign visitors had better regard this as a taboo. Otherwise, if one is bold enough to inquire the other the price of a suit, a car, and the like, it might be considered an insult or despite. Only when one knows the object to be commented on is of a high price and with the intention to please the other, $\mathrm{s} / \mathrm{he}$ is expected to ask about the price.

\subsection{Poverty}

Most of the time, to be poor is something to be ashamed of. Therefore, it is advisable for a foreign visitor not to talk about poverty if he has no adequate knowledge of the conditions in China. Over the past 30 years, the marketing economy has made most of China's families wealthier than ever before, especially in the rural areas where farmers have accumulated money through different but legal means.

But in certain parts of China, generally remote and mountainous areas, most families are still struggling with very modest income due to terrible conditions in geography, climate, and transportation. To help such families free from poverty, all levels of governments in China have implemented favorable policies to ease the difficulty. As a result of the national policy of assisting the poor, the amount of people in poverty has rapidly decreased with the material and policy support from the central government.

The last three decades witnessed great changes in people's attitudes towards poverty and in the meaning of "the poor" (Zhang, 2011). In 1980s when all the Chinese were poor, they seemed to be contended and balanced and even honored to be poor, as long as they could make contributions to the country which keeps growing wealthier and stronger. In 1990s, as the reform and opening policy was going further, a big proportion of the people had become rich; at the same time, there were also many remaining poor. At this time, wealth was respected while poverty contempted. In the first 10 years of the $21^{\text {st }}$ century, the majority of population are much better off. People have 
come to realize that when there is still poverty, it is not because certain people are lazy but because of the difficulty in living conditions. Thus sympathy is the main attitude to poverty at present. Moreover many people are organizing donations, or through other means, to help those in need.

On the other hand, the attitudes of people in poverty also change. They used to be shameful, and then helpless, and now hopeful. To receive various types of support from the government as well as the society, they have to acknowledge and identify themselves as poor in the first place. Whether or not it is out of their own will, the shame-to-yes shift marks a great leap forward.

\section{Health-Related Taboos}

Health has always been a serious topic in China, where people usually avoid talking about diseases on acquaintances. Conversations between close friends, either party with a patient at home, may convey concernedness and encouragement, but should never predict the negative outcome of the disease even if it is very probable.

\subsection{Weight}

With the improvement of living coditions, most people in China are better nutrited and are gaining weight. Thus over-weight has become a common annoyance, to females in particular. Such people try different means to control body weight, such as dieting, exercising, medicating. The heavy burden is not only physical but also psychological. Therefore, it is wise not to talk about weight in relation with such people.

However, for some unknown reason, young men in China are mostly slim and would be delighted to gain some weight. One good example is a sentence often heard "You are growing for the better", the implied meaning of which is that "You are gaining weight". The elderly usually say so as a compliment or encouragement for the younger, while the younger would regard it as something delightful.

\subsection{Disease}

Human beings have a deep-rooted fear of diseases, for they would bring great troubles to the patient and the family, and can even cost a life. Many people in China as well as in other countries believe that some diseases are incurable, like cancers or AIDS. Therefore when they get to know that some acquaintance is identified as this type of patient through diagnosis, the common response is usually sorrow, pity, and helplessness, as if it were the end of the world. However, public attitudes towards AIDS is in sharp contrast with that towards other diseases, because AIDS (venereal diseases indeed), spread through sexual activities or drug abuse, are regarded as "dirty". In recent years, the government and some NGOs in China have made great efforts to help HIV victims, in particular the children who have inherited the fatality from their parents.

In cross-cultural communication, it is a safe choice to avoid talking about disease-related topics; yet it is acceptable to convey encouragement, support, and concernedness between acquaintances; and the will to help may be accepted between familiar ones.

\subsection{Psychosis}

Globalization and urbanalization have assembled more and more people in cities, where there are all kinds of competition, pressure, and challenge, e.g., unemployment, overwork, marriage problems, insufficient income, etc. This has more or less affected the mentality or psychology of people, who may be suffering from depression, mania, or the like.

In China, the same as in many other societies, one's mental or psychological conditions, especially disorders, are highly personal and deemed as taboos. If the patient is some friend or relative of one party in the conversation, it might be acceptable to cover the point, but the topic is strictly limited between people of very close relationships; if the patient is exactly someone present, nobody is expected to mention anything related to psychosis in that case.

With the development of science and pulic knowledge on psychosis, the situation is changing. Tolerance and concern are extended by the acquaintances to such patients or their families more frequently than not. It is advisable for visitors to China never to express even a minor hint of mockery or contempt when socializing with such people.

\subsection{Death}

In China, traditionally, death is a very strict taboo even between acquaintances. When someone has passed away, it should not be mentioned again unless between biological relatives. The outsiders, including the close friends of the family, is merely expected to express their concernedness through sentences like "Take care of yourself!" It is the best way to show respect for and to leave the deceased in peace, which is well seen in the sentence "Do not name the dead." Even on annual mournings, people would usually keep themselves in silent grief.

Over the passed years, traffic accidents are taking place every day; and natural disasters are costing lives in huge 
numbers, e.g., the May-12 Earthquake in Wenchuang of Sichuan Province killed nearly 70,000 people. Death is no longer an unfamiliar word to the Chinese people. But never changed is the idea of respecting the deceased as of supreme priority. As a result, any utterance on death should be better avoided in social conversations.

\section{Festival Taboos}

The major national festivals in China include the Spring Festival/Lunar New Year, the Lantern Festival, the Pure Bright Festival/Tomb Sweeping Day, the Dragon Boat Festival, and the Mid-Autumn Day. On each festival, there is/are certain taboo/s to be watched.

\subsection{Spring Festival Taboos}

Traditionally the Spring Festival lasts from the first day (New Year's Day) to the fifteenth day (the Lantern Festival) of the Lunar New Year. On the Spring Festival, people are expected to keep themselves all clean so as to show holly reverence for the ancestors and immortals. In short, on the Spring Festival, anything bad or dirty is regarded as a taboo. There are many things prohibited: use of any agricultural tools, floor sweep, clean of waste buckets, etc. Verbally, everyone should avoid using "dirty" words like "death" or four-letter words. (Du, 1999:221-222)

Mecidation is strictly a taboo on Lunar New Year, or the subject would suffer from illness and pain all year round.

No travel is allowed on Lunar New Year, for that would indicate a homeless wandering in the following days of the year. Therefore, everyone should stay at home or remain in the community.

Besides, an already-married daughter is not expected to celerate this festival in her parents', for it is believed the good fortune of the family would be brought away when she leaves.

\subsection{Pure Bright Festival Taboos}

The Pure Bright Festival, the Qingming Day in Mandarin, the traditional tomb-sweeping day, which dates back to the Spring and Autumn Period, falls on April 4-6 each year in China. As this day is for memory of the ancestors or family members deceased, there are certain restrictions on people's behavior. People are expected to show up in tidy and dark-color dress and solemn atmosphere, to refrain from laughters and feasts, and to speak in a low voice. When they are sweeping the tombs, silence and reverence are generally required. But as it is in spring, picking of wild vegetables is usually exercised since the graves are mostly in rural areas.

\subsection{Dragon Boat Festival Taboos}

The Dragon Boat Festival, or the Double Fifth Day, on the $5^{\text {th }}$ day of the $5^{\text {th }}$ month in the lunar calendar, is in memory of Qu Yuan a patriot and poet who drowned himself in the river over 2,000 years ago. The biggest event on this day is the dragon boat race, developed from people's unsuccessful effort to save Quyuan on the river. That is the reason why the festival bears its name. But for thousands of years, the Double Fifth Day is in most areas of China regarded as unclean, one possible reason of which is some ugly creatures begin reviving in such a warm season.

The primary taboo on this day is birth, which sounds ridiculous in modern society (Han, 2010). Traditionally it is believed that children born on this day and even in that month would bring misfortune to the familly, the worst of which may cost the lives of the parents. Also babies less than one year old should not spend the day at home; rather they should be brought to their grandparents in law. Children or the newly weds must carry some ornaments of blessing to avoid some intangible vicoius. Doors of houses should be opened on this day and be decorated with certain types of herbs to get rid of evils.

\subsection{Mid-Autumn Day Taboos}

The festival falls on the $15^{\text {th }}$ of the $8^{\text {th }}$ month when the moon is round and bright. It is a time for family reunion, and moon cakes and other delicious food are served for the whole family. Two prevalent taboos on this festival are:

Firstly, newly split-up lovers should not watch the moon, or they would suffer a life-long singularity. And secondly, sexual intercourse should be rigidly prohibited. In TCM (traditional Chinese medicine), the moon is regarded negative or yin, so it is believed that sexual activities upon round moon would harm the health, particularly that of males.

\section{Other Taboos}

Apart from the above categories of taboos, there are still some more for international visitors to notice: marriage, ages, and colors, which are basic yet important as well.

\subsection{Marriage}

The marriage status is always of high sensitivity in most parts of the world. In inter-personal or cross-cultural communications, it is wise to avoid inquiry of marriage. As China is still a relatively traditional nation, no one 
would like to make it pulic that $\mathrm{s} / \mathrm{he}$ is just divorced or remains single when they are no longer young (Gong, 2002, 224).

Moreover, topics on children should also be carefully watched, for some couples may be childless out of different reasons.

6.2 Age

In China, the taboo of age has undergone three stages. Two or three decades ago, it was not yet something to be avoided in talks and chats. But as China opened its door and continues the policy, the ages of females have been respected as private, similar to the western case, up to now. And at present, the ages of males are also regarded as personal, because in a more and more competitive society, a growing age with little achievement may identify a total failure.

\subsection{Colors}

Each country has its traditional recognition of colors with different meanings imbued in them. In China, red, yellow, and purple are the colors for celebration and joy; while black, white, and dark blue are for solemn occasions like especially funerals (Cheng, 2003, 381-384). Therefore, it is very important for visitors in China to make sure of the types of occasions they are to attend and the appropriate colors of garments to be in. Further more, all the pieces of clothing should be in the same style, from hat, to suit, to necktie, to shoes, etc.

\section{Conclusion}

In cross-cultural communication, the foremost task should be the repect of local traditions and customs. As Wolfson $(1983,62)$ ever says, "In interacting with foreigners, native speakers tend to be rather tolerant of errors in pronunciation or syntax; in contrast, violations of rules of speaking are often interpreted as bad manners since the native speaker is unlikely to be aware of sociolinguistic relativity." Taboos are indispensable part of language rules and violation of such rules can probably be interpreted as provocations or confrontations.

It is hoped that the exemplification of such taboos in China would be able to serve as a visitors' guide for cross-cultural communication therein. Without doubt there are many more taboos than those listed in this writing, national or regional, religious or ethical. Like other elements of culture, they are also in constant change, as the world keeps its pace of development.

\section{References}

Cheng, Y. (2003). Highlights of Chinese Culture. Beijing: Foreign Language Teaching and Research Press (Chapter $15)$.

Du, X. (1999). Comparison of Customs between China and English-Speaking Countries. Beijing: Foreign Language Teaching and Research Press (Chapter 15).

Gao, L. (2010). English and Chinese Taboos in Cross-Culural Communication. Journal of Changchun Education Institute, 26, 72-73, 81.

Gong, S. (2002). An Introduction to Chinese Modern Culture. Beijing: Zhonghua Book Company (Chapter 13).

Han, X. (2010). Early Forms of China’s Festival Taboos. Agricultural Archaeology, 4, 112-117.

Lin, D. (1996). Intercultural Communication Studies. Fuzhou: Fujian People's Press (Chapter 2).

Wolfson, N. (1983). Rules of Speaking. In J. C Richards, \& R. W. Schmidt (Eds.), Language and Communication (pp. 61-87). London: Longman.

Zhang, A. (2011). Analysis of Verbal Taboo From the Perspective of Cognitive Linguistics. Journal of Jixi University, 11, 67-69. 